\title{
¿Integridad etnográfica versus estética cinematográfica? El caso de Nosotros los monos (Edmund Valladares, 1971)
}

\author{
Javier Campo' \\ Universidad Nacional del Centro de la Provincia de Buenos Aires
}

Resumo: Este artigo substitui as diferentes visões teóricas sobre ortodoxia e heterodoxia nas relações entre etnografia e cinema através de análise de Nosotros los monos (Nós macacos, Edmund Valladares, 1971). Seran desarrollados conceitos de Karl Heider, Jay Ruby, David MacDougall e Marc Henri Piaul, entre outros; como também procedemos a uma revisão do filme etnográfico argentino do período de 1958-1989 pelas contribuições dos estudos locais sobre ele. Conceituações de Carl Plantinga, na perspectiva formal, aberto e poética, são definidos análise caso dará uma visão geral das particularidades deste tipo de filme documentário em seu desenvolvimento local.

Palavras-chave: cinema etnográfico; Argentina; teoria do cinema.

\footnotetext{
${ }^{1}$ Investigador en cine, doctorado en Ciencias Sociales (Universidad de Buenos Aires). Becario del CONICET (Consejo Nacional de Investigaciones Científicas y Técnicas). Codirector de la revista Cine Documental. Editor asociado de Latin American Perspectives. Profesor de Estética cinematográfica (UNICEN). Autor de Cine documental argentino. Entre el arte, la cultura y la política (2012), compilador de Cine documental, memoria y derechos humanos (2007) y coautor de Directory of World Cinema. Argentina (2014), World Film Locations: Buenos Aires (2014), Una historia del cine político y social en Argentina (2009 y 2011) y Reflexiones teóricas sobre cine contemporáneo (2011), entre otras publicaciones. Miembro del Centro de Investigación y Nuevos Estudios sobre Cine (FFyL-UBA) y del Instituto de Investigaciones Gino Germani (FCS-UBA).
} 


\title{
¿Ethnographic integrity versus film aesthetics? The case of Nosotros los monos (Edmund Valladares, 1971)
}

\begin{abstract}
This article develops the different theoretical views on orthodoxy and heterodoxy in relations between ethnography and cinema through film Nosotros los monos (We Monkeys, Edmund Valladares, 1971) analysis. We set the concepts of Karl Heider, Jay Ruby, David MacDougall and Marc Henri Piault, among others; as also we proceed to a review of the Argentine ethnographic film of the period 1958-1989 by the contributions of local studies on it. Conceptualizations of Carl Plantinga, on formal, open and poetic voices, are set case analysis will give an overview of the particularities of this type of documentary film in their local development.
\end{abstract}

Keywords: ethnography film; Argentina; film theory.

\section{¿Integridade etnográfica versus estética cinematográfica? O caso de Nosotros los monos (Edmund Valladares, 1971)}

Resumen: Este artículo repone los diferentes puntos de vista teóricos sobre la ortodoxia y la heterodoxia en las relaciones entre etnografía y cine a través del estudio del film Nosotros los monos (Edmund Valladares, 1971). Se desarrollan los conceptos de Karl Heider, Jay Ruby, David MacDougall y Marc Henri Piault, entre otros; como asimismo se procede a un repaso del cine etnográfico argentino del período 1958-1989 mediante los aportes de los estudios locales sobre el mismo. Las conceptualizaciones de Carl Plantinga, sobre perspectiva formal, abierta y poética, son las configuran el análisis del caso que dará un panorama de las particularidades de este tipo de cine documental en su desarrollo local.

Palabras clave: cine etnográfico; Argentina; teoría del cine. 
El objetivo específico de este artículo es proceder a un análisis estético del film documental etnográfico argentino Nosotros los monos (Edmund Valladares, 1971) como estudio de caso de un modo de realización guiada por algunos preceptos científicos pero heterodoxa. Este texto se presenta como parte de un estudio más amplio de posdoctorado que focaliza en los films etnográficos argentinos realizados entre las décadas del sesenta y del ochenta, del siglo veinte, para indagar en las similitudes y rupturas formales y temáticas que estos presentan. Enfocando aquellos elementos que aporten a una comprensión de los films como representación de costumbres y prácticas culturales argentinas del período. El objetivo general es hacer una historia analítica y social del cine documental argentino en diálogo con los estudios sociales y culturales.

La investigación se plantea como continuidad de la realizada para la tesis de doctorado (financiada por becas doctorales del Consejo Nacional de Investigaciones Científicas y Técnicas - CONICET). En aquella oportunidad se procedió al análisis formal y narrativo de los films documentales políticos del mismo período en vinculación con los estudios históricos sobre las coyunturas sociales marco. Debido a que el documental etnográfico fue su contemporáneo, el interés de este proyecto es continuar la tarea de indagar en la, parcialmente explorada, historia del cine documental argentino.

En lo que sigue se hará una breve introducción sobre los films etnográficos argentinos más importantes y los (pocos) estudios que sobre los mismos se han desarrollado en el país. Posteriormente se repasarán los principales autores que han definido al cine etnográfico y avanzado en discutir el polémico dilema de la integridad etnográfica (científica) en relación con la estética del cine y las posibilidades de reunir procedimientos audiovisuales y teorías científicas. Finalmente se desarrollará el análisis estético de Nosotros los monos (Edmund Valladares, 1971) para tratar de ejemplificar con este estudio de caso las particularidades de un cine etnográfico con pretensiones artísticas que escapa a los cánones de la ortodoxia cientificista. Cierran este trabajo las conclusiones teóricas y analíticas.

\section{El cine etnográfico argentino en su etapa de soporte fílmico (1958-1989)}

El cine etnográfico se caracteriza, en su conceptualización más tradicional, y la que se aplica por entero al cine documental argentino realizado entre 1958 y 1989, por la documentación de la cultura de un "otro". Su base es el registro de costumbres y prácticas de sujetos marginados que viven en condiciones extemporáneas, diferentes a las de las masas de los centros urbanos. El primer film argentino que registró prácticas culturales ajenas al equipo realizador fue El último malón de Alcides Greca (1918). Esta obra se propuso la representación del "último malón" indígena que fue reducido a principios del siglo XX en la provincia de Santa Fe. También registros producidos por viajeros y exploradores que buscaban paisajes y seres "exóticos" fueron capturados en tierras australes. Gunther Pluschow, un aviador alemán, rodó en la Patagonia Vuelo en imágenes 
hacia mundos desconocidos en 1929. Y, bajo las mismas concepciones de Greca (rescatar las costumbres de un pueblo "en extinción"), los sacerdotes salesianos documentaron a los indígenas fueguinos en Terra Magellaniche (Alberto María de Agostini, 1933).

Han de ser tenidas en cuenta, en este brevísimo recorrido filmogenealógico del cine etnográfico en la Argentina, las dos películas más importantes de la Escuela Documental de Santa Fe: Tire dié (Fernando Birri, 1958) y Los 40 cuartos (Juan Oliva, 1962). Inician la periodización de esta investigación debido a que desde allí se puede hablar de una producción creciente de films documentales etnográficos relacionados, en mayor o menor medida según las obras, con preceptos científicos. Las intenciones de las dos "encuestas sociales filmadas", tal como fueron denominadas por sus creadores, se decantaron por una búsqueda de los caracteres representativos de los habitantes en los márgenes de la ciudad de Santa Fe. Raymundo Gleyzer realizó a mediados de los sesenta algunos films que pueden ser considerados etnográficos por su tema (registro de costumbres culturales populares subalternas) y su enfoque (observación y descripción de tenor sobrio, científico). Luego de La tierra quema (su tesis, filmada en el sertón brasileño en 1964) hizo Ceramiqueros de Traslasierra (1965) y Pictografías del Cerro Colorado (1965), documentales financiados por la Universidad Nacional de Córdoba. Por esos años, gracias a la producción de Ana Montes de González, Gleyzer se asoció con Jorge Prelorán para la realización de Ocurrido en Hualfin (1965) y Quilino (1966).

Sin embargo, la figura sobresaliente del cine etnográfico nacional ha sido Prelorán. Y, asimismo, fue quien más escribió sobre su práctica. Definió con su trabajo y reflexiones lo que entendía por cine etnográfico: ni etnografía ni cine, sino ambas cosas a la vez. ${ }^{2} \mathrm{Ni}$ ciencia, ni arte, pero ubicado en medio de ese campo magnético que ambas esferas irradian. Sin respetar un estricto marco teórico antropológico, Prelorán puso en práctica la observación participante por un tiempo prolongado que, en algunos casos, superó un año de trabajo. Por otra parte, el registro de las actividades de los hombres en un medio natural hostil es otro factor que recorre su filmografía. "Es la zona más brava ésta", dice Hermógenes Cayo en un tono que repiten Damacio Caitruz y Cochengo Miranda (protagonistas de sus films) para caracterizar las regiones en donde viven. Prelorán realizó alrededor de cincuenta documentales etnográficos en la Argentina durante el período comprendido en esta descripción. ${ }^{3}$

Montes de González también se desempeñó como directora. Junto a la antropóloga estadounidense Anne Chapman realizó Los Onas: vida y muerte en Tierra del Fuego (1977). También a fines de la década del setenta Juan Schröder incursionaba en el cine etnográfico con Adiós reino animal (1979) e Inti Anti, camino al sol (1982), promoviendo una mirada ecologista. En los ochenta hicieron su aparición las experiencias fílmicas de Cine Testimonio. Integrado por directores jóvenes como Marcelo Céspedes (Los Totos y Por una tierra nuestra, 1982 y 1984), Tristán Bauer y Silvia Chanvillard (Martín Choque, un

\footnotetext{
${ }_{2}$ "Creo que mis películas - decía Prelorán- no son antropológicas ni etnográficas, sino documentos humanos en los que sólo importa la realidad humana que se va a transmitir. Considero que el cine que hago no es absolutamente objetivo, sino subjetivo, y por lo tanto no es científico. Tampoco creo ser un artista, porque no estoy creando. No me propongo hacer arte, aunque el filme sea parte de un fenómeno estético" (en Ríos, 2005: 111-112).

3 Muchos de estos films fueron realizados en el programa de Relevamiento cinematográfico de expresiones folklóricas argentinas, dirigido por Augusto Raúl Cortazar y financiado por la Universidad Nacional de Tucumán y el Fondo Nacional de las Artes. Asimismo, este ente favoreció la realización de cortometrajes etnográficos de otros directores durante el mismo período.
} 
telar en San Isidro y Ni tan blancos ni tan indios, 1982 y 1984), Víctor Benítez (La Cruz Gil, 1984) y Alberto Giudice; el grupo se conformó para registrar la marginalidad en la que estaban sumidos los sujetos de clases populares. Luego, con Cine Ojo, Marcelo Céspedes y la antropóloga Carmen Guarini seguirían revitalizando la vertiente etnográfica en el cine argentino con Hospital Borda: un llamado a la razón (1985) y Buenos Aires, crónicas villeras (1988).

\section{Estudios sobre documental etnográfico argentino}

Los textos sobre el cine etnográfico argentino han sido producto de aproximaciones a filmografías particulares u obras específicas. Carmen Guarini ha realizado los primeros trabajos ([1984] 2005, 1991) en los que resaltó diferentes films y realizadores. Asimismo, Ricardo Manetti se dedicó a indagar las obras de Cine Testimonio (1994). Por su parte, Andrea Cuarterolo identificó diferentes procedimientos estéticos en obras de documentalistas viajeros en la Argentina de las décadas de 1920 y 1930 (2007 y 2013).

La obra de Jorge Prelorán ha sido la más citada. Juan José Rossi compiló una serie de estudios sobre sus trabajos y entrevistas (1987), Graciela Taquini hizo un balance sobre su carrera (1994), Jorge Ruffinelli propuso un estudio pormenorizado de sus películas más representativas (2003), Marcos Adrián Pérez Llahí se dedicó a un análisis comparativo de su obra y la de Gleyzer (2009) y, por último, el mismo Prelorán publicó una serie de memorias sobre su trayectoria (2006). 4

He publicado algunos artículos sobre cine etnográfico haciendo un balance teórico en consonancia con algunas obras nacionales (REMOVIDO, 2011), como asimismo análisis sobre films en particular: Tire dié (2014a), Hermógenes Cayo (2014b), los documentales realizados en la década del ochenta (junto a Carolina Miori, 2011) y los films de la Escuela Documental de Santa Fe (en coautoría con María Aimaretti y Lorena Bordigoni, 2009). Sin embargo, en ninguno de los textos mencionados en este punto, ni tampoco en los trabajos propios, se ha puesto en práctica una metodología de análisis estético como la que aquí se presentará aplicada a Nosotros los monos. En suma, no se encuentra en la bibliografía de referencia un estudio sistemático del cine etnográfico argentino.

\section{Estudios sobre cine etnográfico}

Las investigaciones sobre cine etnográfico han sido realizadas originalmente por antropólogos. Karl Heider ([1976] 2006) y Jay Ruby (2000) fueron los impulsores de las indagaciones en este campo y, asimismo, los que han defendido un dogma de la realización documental etnográfica (llegando a indicar el uso de determinados tamaños de plano y un montaje "apropiado"). Qué es un film etnográfico ha sido una cuestión arduamente desarrollada y debatida, sobre todo durante el período en que se produjo y estrenó el film de

4 Inclusive se estudia desde los setenta su producción en el exterior. A las menciones de sus films por David MacDougall, Eliot Weinberger y Peter Loizos, en textos que se citarán a continuación, actualmente Christopher Moore, dirigido por Daniel James, está realizando su tesis de doctorado en la Universidad de Indiana (Estados Unidos) sobre la vida y obra de Jorge Prelorán. Su estudio sobre el archivo Prelorán a resguardo en el Smithsonian Institution (Washington) ha sido publicado como "Jorge Prelorán: nativo/extranjero, cineasta/investigador, conservador/revolucionario, desconocido/vastamente conocido”, revista Cine Documental, no 11, Buenos Aires, www.revista.cinedocumental.com.ar. Prelorán vivió gran parte de su vida en Estados Unidos y trabajó en la Universidad de California, Los Angeles (UCLA). 
Valladares (cuestión abordada también recientemente por Paul Basu (2008: 96). Heider destaca que es aquel que está más cerca de los postulados científicos de referencia (en la reedición de su libro afirma una definición más laxa: "una síntesis entre lo científico y lo estético [...] Pero no cualquier film sobre 'otros' es etnográfico, el film sirve de complemento a una investigación etnográfica" 2006: 2-3). 5 La búsqueda de la "integridad" científica del cine etnográfico es una máxima defendida, "el film es una herramienta y la etnografía el objetivo" (Heider, 2006: 3). En resumidas cuentas, para Heider "las distorsiones deben ser mantenidas en un nivel mínimo y usadas para propósitos etnográficos, no por meras razones cinematográficas" (2006: 6). Para Ruby es una falsa dicotomía considerar que "la ciencia antropológica" está en contra del "arte cinematográfico" (2000: 4). Pero, sin embargo, destaca que el cine etnográfico requiere del realizador "tener entrenamiento formal en etnografía [...] Lo que hace a un film 'etnográfico' es su validación científica” (Ruby, 2000: 6). Al final de su estudio concreta su férrea demarcación: "El cine etnográfico debe ser un terreno exclusivo para antropólogos" (2000: 239). Representando similares paradigmas Jack Rollwagen (1995) y Marc Henri Piault (2002) divulgaron postulados sobre el cine etnográfico que subrayan su carácter "científico" por sobre lo "artístico".

Sin embargo, también se han producido investigaciones que atravesaron la historia de este cine de forma heterodoxa: Bill Nichols (1981), David MacDougall (1976, 1992, 1994), Peter Loizos (1993) y Emile de Brigard (1995) presentaron estudios que incluyeron obras experimentales, dejando de lado una caracterización prescriptiva. El caso de MacDougall resulta paradigmático ya que, así como Karl Heider, alternó la realización de films etnográficos con la reflexión teórica. Pero, a diferencia de aquel, no propuso una visión restrictiva para el área de estudios. MacDougall abrió el concepto de cine etnográfico a "cualquier film que busca revelar una sociedad mirada desde otra" (1976: 136). El film "no solo es una herramienta de grabación, sino un lenguaje visual continúa MacDougall -, tener en cuenta ello puede permitir a los films antropológicos la posibilidad de volverse algo más que trabajos científicos para volverse obras artísticas” (1976: 138). Algo negado por las posturas conservadoras anteriormente revisadas. Pero ello no significa menospreciar los conocimientos antropológicos, para MacDougall se debe evitar tanto la "creación de lecturas ilustradas" por films malos, cuanto las "distorsiones etnocéntricas" por malas etnografías (1976: 138). Bajo este punto de vista la historia del cine etnográfico adquiere relevancia para un público más amplio y va, progresivamente, liberándose de estructuras rígidas (con el desarrollo de esta perspectiva no es casual que en los escritos de estos teóricos renovadores se analicen films heterodoxos como los de Jorge Prelorán). Sosteniendo una mirada similar Peter Loizos destaca que él no intenta "demarcar las fronteras entre lo que es etnográfico o no", ya que no le resultan útiles "las reglas y preceptos": "las propuestas de Ruby y Heider son útiles como guías de lectura pero mi práctica es interpretarlas más vagamente de cómo ellos quisieran" (1993: 8).

Una breve, pero interesante, historia del cine etnográfico ha sido la ensayada por Annie Comolli (2009), en un libro colectivo que contiene otros aportes de valor. Asimismo, Eliot Weinberger (1994) y Paul Basu (2008) adosaron a un recorrido fílmico la mención de las diferentes problemáticas 
teóricas que conciernen al cine etnográfico. Con una visión atravesada por los estudios culturales y poscoloniales, en sus diferentes ramificaciones, Faye Ginsburg (1999), Nancy Lutkehaus / Jenny Cool (1999) y Catherine Russell (1999 y 2007- quien acuño el concepto de "etnografía experimental", un oxímoron para los estudios clásicos) ampliaron los análisis sobre este tipo de documental que indaga costumbres y prácticas culturales.

\section{Integridad etnográfica ¿contra? estética cinematográfica}

Es posible destacar un desplazamiento, en los estudios cinematográfico antropológicos, desde la construcción del otro por la diferencia hacia aquella, de influencias marxistas, que se fundamenta en la "desigualdad" de poder. Ruby y Piault acuerdan en que se trata del pasaje que se resiente entre Robert Flaherty y Jean Rouch. Esta última vertiente en el cine etnográfico no puede ser consecuente consigo misma sin promover una reflexión sobre las mismas condiciones de producción del film, incluidas las creencias del realizador. Pero esa reflexión se produjo antes por efectos, usos y factores cinematográficos, o artísticos si se quiere, que por principios estrictamente científicos. La reflexión auto conciente está cada vez más presente en la investigación pero, con resabios fuertes de las ciencias duras, es más lo que se proclama como sabido (casi todos manifiestan la imposibilidad de la absoluta "objetividad científica" en las ciencias humanas) que la puesta en cuestión de la propia subjetividad en los procesos de investigación científica. Por tal motivo, el cine etnográfico es más un desprendimiento del cine que de la antropología, según Adolfo Colombres (2005: 20-21). Es por ello que la afirmación de Ruby, quien dice que los films etnográficos son aquellos realizados "por o en asociación con antropólogos" (Ruby, 2000: 134), entra en conflicto con gran parte de las realizaciones consideradas etnográficas. Es decir, son excluidos Flaherty, John Grierson, Joris Ivens, Raymond Depardon, Johan van der Keuken y otros tantos eslabones en el desarrollo de un cine etnográfico (y en el caso argentino es completamente abandonada tal categoría) o es matizada su definición distanciándola de los principios formativos científicos más duros.

Piault diferencia entre "documentalismo" (cine científico-antropológico, en este caso) y "documental informado" (cine etnográfico). El "documentalismo" pone en imágenes una descripción científica de la realidad, utilizando el material como prueba (algo así como lo que proclamaba Heider). Mientras el "documental informado" representa "datos relativos" sobre la vida de los hombres, cuestionando la extensión de una descripción objetiva. El primero es objeto de una observación antropológica metódica, mientras el segundo se vale de un enfoque antropológico (Piault, 2002: 120). Incursionando decisivamente en esta segunda vertiente será Jean Rouch quién dejará de plantear los films como "meros subproductos en las investigaciones científicas" (Guarini, 1991: 368), y comenzará a desarrollar de manera sistemática este principio. El film ya no será una fuente, una descripción de determinadas actividades, ya no podrá ser considerado como una "evidencia" de lo que hacen los otros, como un "reflejo". El campo de la representación será problematizado, y con él el cine etnográfico llegará a la mayoría de edad.

En tal sentido la diferenciación excluyente entre "integridad etnográfica" y "estética cinematográfica", establecida por Karl Heider (2006: 85) -en la que la indagación sobre la realidad no podrá ser jamás abordada mediante el 
tratamiento creativo de lo real-, será puesta en crisis por las nuevas corrientes en el cine etnográfico. En el cine etnográfico, considerado por muchos como el más ortodoxo de los discursos de la sobriedad documental, comenzó a aflorar en las últimas décadas una práctica ubicable -siguiendo a Bill Nichols- dentro de la modalidad performativa, como aquella en la cual los elementos expresivos no se supeditan a ninguna estructura rígida prefiriendo la sugerencia a la explicación (Nichols, 2003: 204-210). Inclusive se llegó a concebir el concepto de "etnografía experimental", impensable hasta hace poco, acuñado por Catherine Russell para designar "una incursión metodológica de la estética en la representación cultural, una colisión entre la teoría social y la experimentación formal" (en Weinrichter, 2005: 58). Para Russell se trata de romper las barreras entre las vanguardias buscando los indicios de "lo social" por una práctica cultural que fusione la innovación estética y la observación social (Russell, 2007: 138). Siguiendo el mismo proceso contemporáneo del cine documental en su conjunto "la etnografía se libera - de esta manera- de su vínculo con lo real y de sus supuestos sobre la verdad y el significado" (Russell, 2007: 131) ${ }^{6}$. Por ello el cine etnográfico actual no debe eludir el peligro histórico de "convertirse en arte", sino asumir que la etnografía "puede incluso considerarse una práctica experimental donde teoría estética y cultural se fusionan" (Russell, 2007: 134). A pesar de estas innovaciones en el plano discursivo la representación del mundo social e histórico no es elidida, sino que sigue constituyendo la materia del talante referencial del mensaje.

\section{Metodología de análisis}

En la indagación del estudio de caso representativo del cine documental etnográfico argentino se utilizará, adecuada a su especificidad, una metodología de análisis estético. Se dividirán todas las secuencias según su autoría: 1) imagen y sonido propios, 2) imagen ajena y sonido propio, 3) imagen propia y sonido ajeno e 4) imagen y sonido ajenos. "Propio" significará aquí generado para el film, de factura propia del realizador; mientras que "ajeno" querrá decir imágenes o sonidos tomados de otros films, o bien de publicaciones gráficas, fotografías, música o programas de radio y televisión. Esta división resulta operativa para identificar procedimientos, modalidades, perspectivas $\mathrm{y}$ funciones aislándolas para su estudio pormenorizado.

En cada uno de estos cuatro puntos de análisis se subdividirá el estudio teniendo en cuenta los procedimientos formales más frecuentemente utilizados en el cine documental: la voz over, el testimonio, el registro de observación y el material de archivo. Mediante las conceptualizaciones de Bill Nichols (1988) sobre la voz over, Gustavo Aprea (2012) -el testimonio-, María Luisa Ortega / Noemí García (comps., 2008) -registro de observación- y Jay Leyda (1964) material de archivo-, entre otros autores, sobre la relevancia de cada uno de esos procedimientos técnicos; de esta forma obtendrá fundamento teórico la metodología adoptada.

Por otra parte, se explorará la tríada de análisis de Carl Plantinga. Prestando atención a "las gradaciones de la autoridad narrativa asumida por los

\footnotetext{
${ }^{6}$ La autobiografía se constituye en una de las formas más transitadas de etnografía experimental. Modificando así de plano la noción clásica de etnografía, como aquella dedicada al estudio de los "otros" (Russell, 2007: 147). Michael Renov es quien probablemente haya sido quien ha estudiado más en profundidad las prácticas performativas en su encuentro con la etnografía en el documental. Véase, por ejemplo, su "Domestic etnography and the construction of the 'other' self' (Renov, 1999).
} 
films o la ausencia de la misma en favor de preocupaciones estéticas" elabora tres perspectivas generales (Plantinga, 1997: 106). La perspectiva formal utiliza los elementos de la representación para explicar sosteniendo una fuerte "función comunicativa" que tiende a configurar una estructura del film "simétrica, unificada y 'cerrada" (Plantinga, 1997: 107). Contrapuesta a ésta se presenta la perspectiva abierta, que "es más reticente a la impartición de conocimiento presunto" (Plantinga, 1997: 108). Más que explicar, observa. Por último, se encuentra la perspectiva poética. Asociada al film de arte o a la "explorativa representación de sí mismo", esta perspectiva busca un efecto estético, en el sentido que presta "excesiva atención a la 'belleza' o a las cualidades sensuales de los objetos" (Plantinga, 1997: 109). Las diferencias entre las tres perspectivas "no radican en la postura afirmativa que toman hacia el mundo proyectado, sino en la posición discursiva de autoridad epistémica, vacilación o esteticismo" (Plantinga, 1997: 109). En definitiva, la perspectiva formal sirve para hacer reivindicaciones o informar sobre cuestiones puntuales, la abierta para representar las apariencias y dejar que los espectadores infieran generalizaciones y la poética "pone en primer plano las cualidades estéticas de lo que presenta" (Plantinga, 1997: 110). Sin embargo, ninguna de ellas comanda libre de la presencia de las demás la estructuración de sentidos dentro de un mismo film.

\section{Nosotros los monos}

Nosotros los monos (Edmund Valladares, 1971) es un documental que indaga críticamente en el mundo del boxeo.7 Valladares ejerce un análisis deconstructivo de los fundamentos del boxeo para contraponerlo a la penosa evidencia de "accidentes" de irreversibles consecuencias y muertes sobre el ring. Una crítica humanista que, no llega a adherir a una descripción negativa de las estructuras de poder de la sociedad en general, pero que indaga en una práctica social asociada al mercado en el cual los seres humanos se vuelven piezas de una máquina de consumo.

La película es un gran alegato contra el sistema que sostiene al mundo del boxeo profesional (integrado por managers, empresarios, publicidad, periodismo y público) y una muestra de cómo el negocio de este deporte utiliza y engaña, en sus ilusiones de progreso, a los jóvenes del interior con el fin de ganar más dinero. El gran eje es el problema de la identidad: del chico del interior que movido por la pobreza que vive en su lugar de origen se desplaza a la gran ciudad con expectativas de evolución social. A partir de este conflicto el film denuncia al mundo del boxeo como un exponente más de la gran maquinaria que se nutre y funciona gracias a la desgracia del inmigrante interno. Los jóvenes, ahora boxeadores, son tentados con promesas de dinero y gloria, explotados y desechados una vez que ya no funcionan arriba del ring. (Addunci Spina y Morales, 2010: s/p)

\section{Relato poético}

En el comienzo del film se destaca como lugar de nacimiento de los boxeadores los ranchos y villas del interior del país. Aparecen niños en planos

7 Una descripción que consigna detalles del film y su autor, como asimismo un fragmento del mismo, puede consultarse en: www.museovalladares.com.ar/cine.html 
amplios y cortos jugando y mirando a cámara mientras el locutor señala que "de aquí se surte el mercado de la materia prima. Este es el semillero. Esta es la fábrica. Son el elemento indispensable. Si no van a la escuela mucho mejor, dejándolos con toda su esencialidad, sin contaminarlos. En condiciones ideales para que los enganche el engranaje”. El relato en el film de Valladares es en gran parte poético, persuasivo y por momentos agresivo con el boxeo y quienes viven (o mueren) por él. Gran parte de los planos son amplios y generales con uso de cámara fija, las imágenes no pretenden la observación e indagación en el vínculo de las clases populares y el boxeo, sino servir como ilustración a una fuerte postura ideológica al respecto, manifestada en el discurso verbal. En algunas secuencias de este film el carácter informativo del discurso se vuelve denso para dar cuenta de la investigación que se realizó para determinar la relación entre ex boxeadores y dementes internados en hospitales psiquiátricos. Pero siempre vuelve a sus giros poéticos: "La ciudad te golpeó en tus esperanzas y utilizó tus necesidades de vivir como hombre. Aunque te había contratado de payaso para el espectáculo de nosotros, los verdaderos monos", mientras un sonido de ambulancia e imágenes de una autopista iluminada en travelling en reversa y con encuadres oscilantes recrudece la tensión de este relato.

En Nosotros los monos el locutor simula un diálogo con Mario Paladino, boxeador tendido en el ring, muerto, "Indio, te han golpeado, los guardias del espectáculo te dan la posibilidad de que te rehabilites. Ya estás vencido. Estás caído esta vez para siempre. Las sogas no te dejarán escapar de tu lecho de lona, colocan a tu vencedor un collar de hienas”. El discurso poético por momentos del narrador no deja de lado su carácter retórico, su alocución sigue yendo en una dirección definida: el boxeo no es un deporte, sino "violencia reglamentada".

\section{Experimentación}

En Nosotros los monos (Edmund Valladares, 1971) se presentan algunas secuencias que generan una representación en la que imágenes, sonidos y palabras están imbricadas y no son subsidiarias unas de otras. Mediante la utilización de encuadres cerrados sobre elementos en movimiento en la ciudad de Buenos Aires (colectivos, autos, personas), y con sonido ambiente, el locutor remarca que "la ciudad se impondrá con incoherentes muñecos. Computando la necesidad por sobrevivir. El viaje hacia la máquina ha comenzado junto a propio desarraigo". El uso del encuadre cerrado y del zoom in sobre luces y objetos en movimiento acompaña la sensación de agobio y frenetismo que Buenos Aires parece generar en los recién llegados. En las últimas secuencias el llamado provocativo a la reflexión sobre las características inhumanas del boxeo se recrudece con las imágenes del funeral de Mario Paladino, boxeador muerto en el cuadrilátero, que capturan en plano medio a los asistentes, mientras el locutor juega sus últimas fichas: "se quiere consolar a familiares y amortiguar responsabilidades de todos. Lo único que entienden es que un día Mario cargó sus guantes con la esperanza de recoger pan para ellos. Ahora los guantes están vacíos”. Otra secuencia también está construida bajo similar aproximación formal. Insertada entre las secuencias informativas y retóricas sobre la actividad boxística hay un conjunto de planos, repetidos al final del film, en los que con música coral unos niños galopan en cámara lenta sobre unos burros, seguidos en un travelling en reversa. 


\section{Agresividad descriptiva}

Para impactar sobre lo que el realizador considera una práctica peligrosa y asocial, y persuadir sobre su impacto negativo, no se busca la empatía con los personajes del film, los espectadores que pudiesen estar interesados en el boxeo o los migrantes internos idos a Buenos Aires. El relato es extremadamente agresivo por momentos: "en el cuadrilátero adquiere el mote que siempre tiene que ver con animales o personajes más primitivos: pantera, toro, tigre, indio, mono", mientras se ven boxeadores en primer plano de frente que sonríen. "Las estadísticas de los reformatorios son elocuentes - dice la voz over en otra secuencia, mientras se montan imágenes de adolescentes sentados en una vereda- de cien que entran, cincuenta son del interior. Urge ganarse la vida de cualquier manera, su fuerza puede ser bien empleada en el box". Los migrantes y los jóvenes de extracción popular son estigmatizados como inocente "carne de cañón" (se utiliza en otra secuencia este término), en repetidas ocasiones como "engranaje" de la máquina mercantil o como sujetos de simpleza "animal". "Se entienden fácil, un amago y ambos se confiarán sus ilusiones”, dice el locutor mientras son registrados con teleobjetivo jóvenes en plazas que, para el realizador, son tan simples (o primitivos) que se entienden prácticamente sin necesidad de palabras.

\section{Voces}

Este es un film en el que es difícil discernir entre una voz formal, informativa y otra caracterizada (es decir, una cita verbal de palabras de otros). Salvo en la secuencia mencionada en el punto anterior (de eminente tono descriptivo e informativo), la voz del narrador (el actor Luis Medina Castro) discurre entre los tonos poético, formal y persuasivo presentes en el guión escrito por el mismo director. Luego de la introducción se afirma que "el 'reportaje' sube al cuadrilátero donde se desarrollará el festín de la violencia. Para considerarlo espectáculo es necesario llamarlo deporte, entonces se convierte en violencia reglamentada", las imágenes de archivo repiten alrededor de veinte veces- a boxeadores subiendo al ring y saludando. A continuación y en un plano amplio de espectadores se precisa la idea general: "uno como público va como al cine, a ver si pasa algo. Pero ese 'algo' en cine es ficción. En el cuadrilátero es un supermercado de muelas que se aflojan, hematomas o contusiones. De cualquier manera siempre es la misma historia: pan y circo". A medida que las imágenes de peleas se suceden el discurso se va volviendo más agresivo: "dos seres humanos se están convirtiendo en bestias y es posible que una destroce a la otra [...] Los síntomas son progresivos y podrán convertirlos en criminales, incendiarios, violadores, etc.” El uso de las imágenes suele ser de impacto en este film, el montaje de puñetazos y caídas de boxeadores grogui se detiene en la presentación de un esquema: "a través del diagrama podemos observar cómo se interna el golpe lesionando el lóbulo frontal. El deterioro del tejido celular causará la muerte mental". La ilustración sobre el cerebro en una cabeza que recibe un puñetazo muestra didácticamente el daño cerebral que las palabras intentan dejar en claro. Este tipo de esquemas e ilustraciones no son comunes entre el conjunto de films etnográficos argentinos realizados entre 1958 y 1989, su uso en la película de Valladares es 
altamente didáctico. "Tal vez si no le contaran se preguntaría qué hace ahí, porqué se dedicó a eso que le dijeron que era un deporte. Su estado sólo le permitirá balbucear", dice el locutor mientras boxeadores caen y se levantan en el cuadrilátero; este es uno de los últimos intentos del narrador para dar cuenta del carácter sanguinario de la práctica del boxeo.

\section{Ironía crítica}

En la película de Valladares se hace presente un tipo de ironía crítica que fortalece la postura ideológica del realizador con respecto al carácter dañino, animal y capitalista del boxeo. Por ejemplo se puede citar el uso de una canción religiosa que dice "soy feliz por haber comprendido que con Cristo se vive mejor", es la letra de un tema presente en una secuencia acompañando distintos planos de peleas de boxeo. La yuxtaposición es flagrante y por montaje de choque se establece el llamado de atención al espectador (aparentemente mucho más "elevado" intelectualmente que los miembros del mundo del boxeo). Asimismo, las imágenes de boxeadores que reciben puñetazos y caen sobre el cuadrilátero buscan persuadir del carácter nocivo del boxeo. La sucesión da forma a un montaje discursivo.

El único plano de archivo con sonido sincrónico que se inserta es el de la última entrevista a Mario Paladino antes de fallecer en el ring (esto es informado mediante un título). En un primerísimo primer plano dice "pienso de que tengo plena confianza en mí mismo. Creo que vengo bien”. Las palabras se demuestran trágicamente críticas dado el desenlace posterior y muerte del entrevistado. Su uso, aunque rompe con la estética construida en el film, está plenamente justificado por la presencia posterior de las imágenes de esa pelea y el velorio con el que termina la película de Valladares.

\section{Conclusión}

Nosotros los monos (Edmund Valladares, 1971) es un film heterodoxo que escapa a la mentada, por Heider, "integridad etnográfica”. Su director es un artista y no un antropólogo y, aunque fue asesorado por científicos (psiquiatras), no realizó su film siguiendo preceptos de la investigación científica rigurosos. Sin embargo el film nos otorga una cantidad de información sobre la problemática social del boxeo y sus participantes que no es relegada en pos del cuidado trabajo estético con que el documental está realizado. Es decir, parafraseando a MacDougall, no es solo un trabajo científico, es también una obra artística.

Sin embargo en el desarrollo del análisis pudo darse cuenta de que, más allá de la experimentación y el relato poético e irónico utilizado en Nosotros los monos, la perspectiva que prima, haciendo uso de la conceptualización de Plantinga, no es la "poética", ni siquiera la "abierta", sino la "formal". Debido a que el discurso del director está ampliamente presente y no es cuestionado por ninguna "voz" en el desarrollo de las ideas presentadas en la narración. En definitiva, la película de Valladares hace uso de diversos tipos de recursos cinematográficos que se alejan de las recomendaciones de Ruby y Heider sobre lo "propiamente" etnográfico, aunque su discurso es cerradamente formal: el realizador presenta sus ideas críticas sobre el boxeo sin inflexiones en el discurso ni relatos que lo contradigan. 
El cine científico-antropológico como aquel que "sirve" como la libreta al investigador, está asociado a la afirmación de Ruby sobre la necesidad de ser dirigido, o asesorado, por un antropólogo; o a la diferenciación establecida por Heider. En consonancia con ellos, Jack Rollwagen destaca que "el cine antropológico no es simplemente la grabación de lo que el ser humano dice o hace, sino la interpretación de estas grabaciones en el marco de la disciplina antropológica, incluyendo la totalidad del proceso de filmación, desde su concepción hasta su ejecución" (Rollwagen, 1995: 338). Sin embargo, circulando por otros carriles, cierto cine etnográfico sin pretensiones objetivistas fisura esos marcos e introduce otros parámetros de interpretación o, incluso, representa costumbres culturales sin proceder a explicaciones científicas concluyentes. Tal como Nosotros los monos (Edmund Valladares, 1971), que puede decir mucho sobre las costumbres culturales argentinas de un período si exploramos entre sus fisuras, así como otros films documentales que han sido sus contemporáneos.

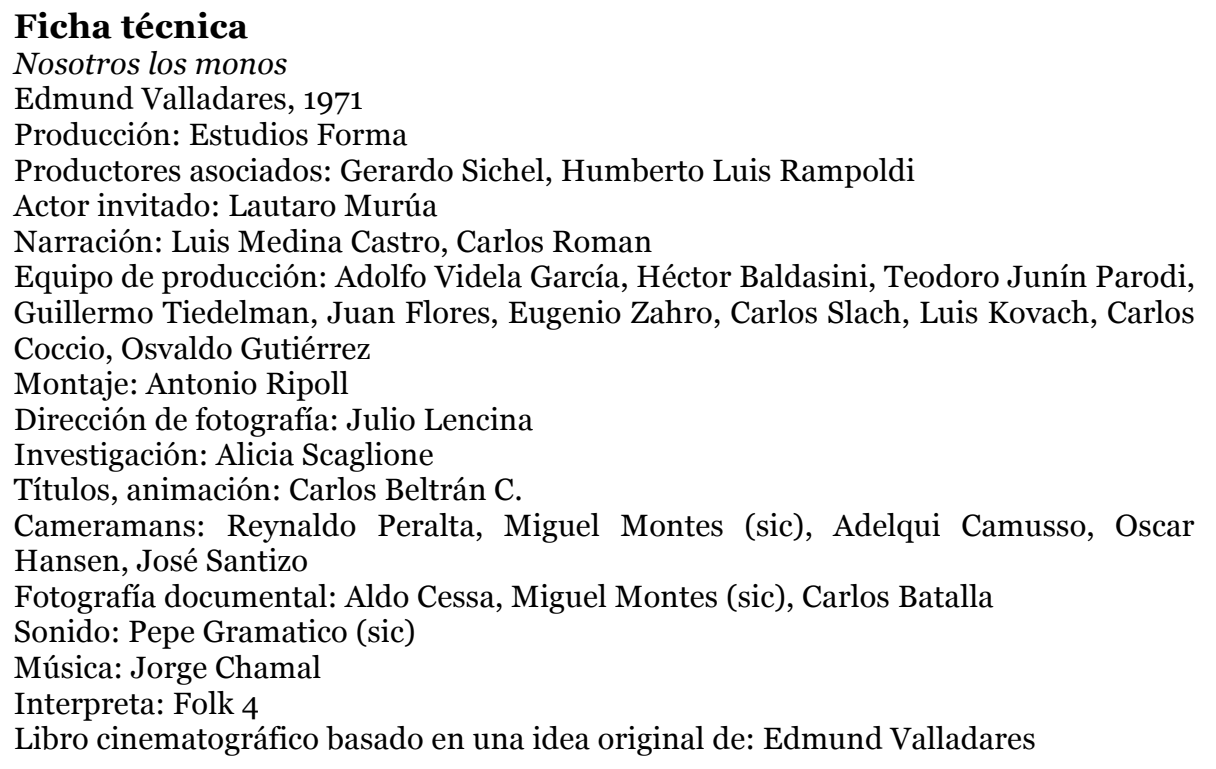

\section{Referencias}

ADDUNCI SPINA, Elina y MORALES, Iván. Nosotros los monos. Inédito, 2010.

AIMARETTI, M.; BORDIGONI, L. y CAMPO, J. "La escuela documental de Santa Fe. Un ciempiés que camina”. In: LUSNICH, A. L. y PIEDRAS, P. (eds.). Una historia del cine político y social en Argentina. Formas, estilos y registros (1896-1969). Buenos Aires: Nueva Librería, 2009.

APREA, G. "Los usos de los testimonios en los documentales audiovisuales argentinos que reconstruyen el pasado reciente". In: APREA, G. (comp.). Filmar la memoria. Los documentales audiovisuales y la re-construcción del pasado. Los Polvorines: Universidad Nacional de General Sarmiento, 2012.

BASU, P. "Reframing Ethnographic Film". In: AUSTIN T. y DE JONG, W. (eds.). Rethinking Documentary. New Perspectives. New Practices. Berkshire: Open University Press, 2008. 
BRIGARD, E. "Historia del cine etnográfico". In: ARDEVOL E. y PÉREZ TOLÓN, L. (eds.). Imagen y cultura. Perspectivas del cine etnográfico. Granada: Diputación Provincial de Granada/Biblioteca de Etnología, 1995.

CAMPO. J. "El medio hostil. Fundamentos y recorridos del cine etnográfico en la Argentina”. In: LUSNICH, A. L. y PIEDRAS, P. (eds.). Una historia del cine político y social en Argentina. Formas, estilos y registros (1969-2009). Buenos Aires: Nueva Librería, 2011.

CAMPO. J. “Toss me a dime (Tire Die)”. In: URRACA B. y KRAMER G. (eds.). Directory of World Cinema: Argentina. Bristol - Chicago: Intellect Books, 2014a.

CAMPO. J. “Imaginero (Hermógenes Cayo)”. In: URRACA B. y KRAMER G. (eds.). Directory of World Cinema: Argentina. Bristol - Chicago: Intellect Books, 2014b.

CAMPO. J. y MIORI, C. De virtudes y miseria. El cine etnográfico de la década del ochenta. In: LUSNICH, A. L. y PIEDRAS, P. (eds.). Una historia del cine político y social en Argentina. Formas, estilos y registros (1969-2009). Buenos Aires: Nueva Librería, 2011.

COMOLLI, A. "Elementos de método em antropologia fílmica”. In: FREIRE, M. y LOURDOU, P. (orgs.). Descrever o visível. Cinema documentário $e$ antropologia fílmica. Sao Paulo: Editora Estaçao Liberdade, 2009.

CUARTEROLO, A. "El cazador de sombras, la representación del indígena fueguino en la obra documental del sacerdote Alberto María de Agostini”. In: CAMPO, J. y DODARO, C. (comps.). Cine documental, memoria y derechos humanos. Buenos Aires: Nuestra América, 2007.

CUARTEROLO, ANDREA. De la foto al fotograma. Relaciones entre cine y fotografía en la Argentina (1840-1933). Montevideo: CDF Ediciones, 2013.

GINSBURG, F. "The parallax effect: The impact of indigenuos media on etnographic film”. In: GAINES, J. y RENOV, M. (comps.). Collecting Visible Evidence, Volume 6. Minneapolis: University of Minnesotta Press, 1999.

GUARINI, C. "Cine y antropología. De la observación directa a la observación diferida”. In: GUBER, R. El salvaje metropolitano. Buenos Aires: Legasa, 1991.

GUARINI, C. "Cine antropológico: algunas reflexiones metodológicas". In: COLOMBRES, A. (ed.). Cine, antropología y colonialismo. Buenos Aires: Ediciones del sol, 2005.

HEIDER, KARL. Ethnographic Film. Austin: University of Texas Press, 2006.

LEYDA, Jay. Films beget films. A study of the compilation film. New York: Hill and Wang, 1964.

LOIZOS, Peter. Innovation in ethnographic film. From innocence to selfconsciousness (1955-1985). Chicago: University of Chicago Press, 1993.

LUTKEHAUS, N. y COOL, J. "Paradigms lost and found: The "Crisis of Representation' and Visual Anthropology". In: GAINES, J. y RENOV, M. (comps.). Collecting Visible Evidence, Volume 6. Minneapolis: University of Minnesotta Press, 1999. 
MACDOUGALL, D. "Prospects in the Ethnographic Film". In: NICHOLS, B. (ed.). Movies and Methods. An anthology. Berkeley: University of California Press, 1976.

MACDOUGALL, D. "Complicities of style”. In: CRAWFORD, P. y TURTON, D. (eds.). Film as ethnography. Manchester: University of Manchester Press, 1992.

MACDOUGALL, D. "Whose story is it?" In: TAYLOR, L. (ed.). Visualizing Theory. New York: Routledge, 1994.

MANETTI, R. “Cine testimonial”. In: ESPAÑA, C. (comp.). Cine argentino en democracia 1983-1993. Buenos Aires: Fondo Nacional de las Artes, 1994.

NICHOLS, BILL. Ideology and The Image. Social Representation in the Cinema and Other Media. Bloomington: Indiana University Press, 1981.

NICHOLS, B. "The voice of documentary". In: ROSENTHAL, A. (ed.). New Challenges for documentary. Berkeley: University of California Press, 1988.

ORTEGA, MARÍA LUISA y GARCÍA, NOEMÍ (comps.). Cine directo. Reflexiones en torno a un concepto. Madrid: T\&B Editores, 2008.

PÉREZ LLAHÍ, M. A. "La tierra es del que la ha perdido. A propósito de Raymundo Gleyzer y Jorge Prelorán”. In: LUSNICH, A. L. y PIEDRAS, P. (eds.). Una historia del cine político y social en Argentina. Formas, estilos y registros (1896-1969). Buenos Aires: Nueva Librería, 2009.

PIAULT, MARC HENRI. Antropología y cine. Madrid: Cátedra, 2002.

PLANTINGA, CARL. Rhetoric and representation in nonfiction film. Cambridge: Cambridge University Press, 1997.

PRELORÁN, JORGE. El cine etnobiográfico. Buenos Aires: Ediciones Universidad del Cine: Catálogos, 2006.

ROLLWAGEN, J. "La función de la teoría antropológica en el cine etnográfico". In: ARDEVOL E. y PÉREZ TOLÓN, L. (eds.). Imagen y cultura. Perspectivas del cine etnográfico. Granada: Diputación Provincial de Granada/Biblioteca de Etnología, 1995.

ROSSI, JUAN JOSÉ (comp.). El cine documental etnobiográfico de Jorge Prelorán. Buenos Aires: Ediciones Búsqueda, 1987.

RUBY, JAY. Picturing Culture. Explorations of Film \& Anthropology. Chicago: University of Chicago Press, 2000.

RUFFINELLI, J. “Jorge Prelorán”. In: PARANAGUÁ, P. A. (ed.). Cine documental en América Latina. Madrid: Cátedra / Festival de Málaga, 2003.

RUSSELL, CATHERINE. Experimental ethnography. The work on film in the age of video. Durham - London: Duke University Press, 1999.

RUSSELL, C. Otra mirada. In: CATALÁ, J. M. y CERDÁN, J. (eds.). Después de lo real. Valencia: Archivos de la Filmoteca, num. 57-58, Vol. 1, 2007.

TAQUINI, Graciela. Jorge Prelorán. Buenos Aires: Centro Editor de América Latina, 1994.

WEINBERGER, E. “The Camera People”. In: TAYLOR L. (ed.). Visualizing Theory. New York: Routledge, 1994. 